\title{
Subthalamic Nucleus Lesions Enhance the Psychomotor- Activating, Incentive Motivational, and Neurobiological Effects of Cocaine
}

\author{
Jason M. Uslaner, Pengwei Yang, and Terry E. Robinson \\ Biopsychology and Neuroscience Programs, Department of Psychology, University of Michigan, Ann Arbor, Michigan 48019-1109
}

\begin{abstract}
The subthalamic nucleus (STN) is traditionally thought to be involved in motor control, and dysfunction of the STN is thought to contribute to movement disorders. Here, we show that the STN also plays an important role in motivational processes and the response to drugs of abuse. Specifically, bilateral STN lesions produced a dose-dependent increase in the psychomotor-activating effects of cocaine, the rate at which animals acquired cocaine self-administration, and the motivation for cocaine assessed using a progressive ratio schedule. Furthermore, bilateral STN lesions enhanced the ability of cocaine to induce gene expression in the nucleus accumbens and caudate-putamen, two structures known to be involved in mediating the psychomotor-activating and incentive motivational effects of drugs of abuse. These findings suggest that engagement of the STN serves to dampen the psychomotor-activating and incentive motivational effects of drugs of abuse. Thus, the STN may serve as a novel target for therapeutic interventions aimed at treating drug dependence.
\end{abstract}

Key words: nucleus accumbens; caudate-putamen; c-fos; progressive ratio; acquisition; self-administration

\section{Introduction}

Neural systems that mediate the behavioral effects of drugs of abuse have been well studied, and it is known that these drugs enhance psychomotor activation and produce their reinforcing and incentive motivational effects, at least in part, by altering dopaminergic transmission in the medial prefrontal cortex (mPFC), nucleus accumbens (NAcc), and caudate-putamen $(\mathrm{CPu})$ (Wise and Bozarth, 1987). Although the behavioral function and neuronal properties of dopamine-containing cells and their direct targets have been well characterized (Schultz, 1997; Carelli and Wightman, 2004), relatively little is known about the contribution of structures that receive inputs from dopaminerich brain regions.

One important target of the striatum (caudate-putamen and nucleus accumbens) and the mPFC is the subthalamic nucleus (STN) (Kita and Kitai, 1987; Groenewegen and Berendse, 1990; Maurice et al., 1998). The STN is traditionally considered to be important in motor control, in part because of its presumed involvement in movement disorders (Albin et al., 1989; Crossman, 1990). The role of the STN in more "limbic system"-related functions, such as motivation and the behavioral and reinforcing effects of drug of abuse, has received much less attention. However, recently, it has been shown that amphetamine and cocaine induce robust c-fos expression in the STN (Uslaner et al., 2001a),

\footnotetext{
Received May 12, 2005; revised Aug. 2, 2005; accepted Aug. 2, 2005

This work was supported by a grant from the National Institute on Drug Abuse to T.E.R. (R37-DA004294). We thank Carrie Ferrario and Jakub Jedynak for their technical assistance and Dr. Martin Sarter for helpful comments.

Correspondence should be addressed to Dr. Jason M. Uslaner, Department of Psychology, Biopsychology Program, University of Michigan, East Hall, 525 East University Street, Ann Arbor, MI 48019-1109. E-mail: juslaner@umich.edu.

DOI:10.1523/JNEUROSCI.1910-05.2005

Copyright $\odot 2005$ Society for Neuroscience $\quad$ 0270-6474/05/258407-09\$15.00/0
}

which sensitizes as a result of repeated drug administration (Uslaner et al., 2003b) and that bilateral lesions of the STN increase responding for food rewards (Baunez et al., 2002). Furthermore, high-frequency electrical stimulation (HFS) of the STN, which is used to treat symptoms of Parkinson's disease, also enhances motivation and other limbic system-related processes in these patients (Funkiewiez et al., 2003; Takeshita et al., 2005). These studies suggest, therefore, that in addition to its involvement in motor control, the STN may play a role in motivational processes and the behavioral response to drugs of abuse.

Here, we sought to clarify the role of the STN in the behavioral and neurobiological effects of one drug of abuse, cocaine. Specifically, we examined the influence of bilateral STN lesions on cocaine-induced psychomotor activation, the acquisition of cocaine self-administration, motivation for cocaine assessed using a progressive ratio (PR) schedule, and cocaine-induced c-fos mRNA expression. Our results indicate that the STN plays an important and specific role in inhibiting the reinforcing and psychomotor-activating effects of cocaine and suggest that the STN may serve as a novel target for therapeutic intervention aimed at treating drug addiction.

\section{Materials and Methods}

Influence of bilateral STN lesions on cocaine-induced psychomotor activation

Subjects. Thirty-one male Sprague Dawley rats (Harlan, Indianapolis, IN) weighing 225-250 g were housed individually in clear square plastic cages and were given a 1 week acclimatization period before any experimental manipulation. The rooms were temperature- and humiditycontrolled and maintained on a 14/10 h light/dark cycle (lights on at 7:00 A.M.), with food and water available ad libitum. All experimental procedures were approved by the University of Michigan Committee on the Use and Care of Animals. 
Surgical procedures. Rats were anesthetized with ketamine hydrochloride (100 mg/kg, i.p.; Fort Dodge Animal Health, Ford Dodge, IA) and xylazine hydrochloride $(1.5 \mathrm{mg} / \mathrm{kg}$, i.p.; Ben Venue Laboratories, Bedford, $\mathrm{OH}$ ) and secured into a stereotaxic apparatus. Twenty-two rats were randomly chosen to receive bilateral injections of ibotenic acid $(12.5 \mu \mathrm{g} / \mu \mathrm{l}$; in 0.1 м PBS, pH 7.4; Tocris Cookson, Ellisville, MO), and the remaining nine rats received vehicle alone $(0.1 \mathrm{~m}$ PBS). The volume injected was $0.5 \mu \mathrm{l}$ per side infused over 3 min using a $10 \mu$ l Hamilton syringe connected by tubing fitted to a 30 gauge stainless-steel injector needle. A micropump was calibrated to deliver the exact volume of fluid.

The coordinates targeting the subthalamic nucleus were measured from bregma: anterior/posterior, $-3.8 \mathrm{~mm}$; lateral, $+2.4 \mathrm{~mm}$; dorsal/ ventral, $-8.35 \mathrm{~mm}$ (from skull). Valium (diazepam; $5 \mathrm{mg} / \mathrm{kg}$, i.p) was administered before recovery from anesthesia to prevent convulsions.

Testing procedures. After 12-14 d recovery from surgery, animals were transferred to locomotor test cages, which were clear rectangular tubs $(22 \times 45 \times 23 \mathrm{~cm})$ containing a clear plastic insert in the center of the cage $(6.5 \times 23 \times 23 \mathrm{~cm})$ that formed a corridor through which rats could locomote. Two sets of infrared photocells were located along the length of the chamber ( $23 \mathrm{~cm}$ apart), and crossovers were recorded (defined by consecutive breaks of each set of infrared photocells) as an index of locomotor activity.

On the first test day, after $60 \mathrm{~min}$ of habituation to the test cages, each animal received intraperitoneal injections of escalating doses of cocaine hydrochloride $(0,7.5,15$, and $30 \mathrm{mg} / \mathrm{kg}$; weight of the salt; dissolved in $0.9 \%$ saline). Each injection was separated in time by $30-90 \mathrm{~min}$, and behavior was recorded. On the following $4 \mathrm{~d}$, animals were brought to the test cages, habituated for $60 \mathrm{~min}$, and then given $15 \mathrm{mg} / \mathrm{kg}$ cocaine and left in the cages for an additional $60 \mathrm{~min}$. After $2 \mathrm{~d}$ off drug, animals were once again given escalating doses of cocaine using the same procedure as on the first day. This dosing regimen allows for the construction of a dose-response function for the first and last day of treatment (Li et al., 2004). Sensitization is indicated by a shift to the left in the dose-response curve.

Verification of lesion. After the completion of testing, animals were deeply anesthetized with isoflurane, decapitated, and their brains were removed, frozen in isopentane on dry ice, and stored at $-70^{\circ} \mathrm{C}$. Brains were sectioned using a cryostat, and $16 \mu \mathrm{m}$ coronal sections were thawmounted to Superfrost/Plus slides (Fisher Scientific, Pittsburgh, PA) and stained with cresyl violet to examine the extent of the lesions.

To further characterize the extent of the lesion, the neuron-specific nuclear protein (NeuN) was labeled using immunocytochemistry. Slidemounted sections were incubated in $4 \%$ paraformaldehyde, $\mathrm{pH} 7.4$, for $1 \mathrm{~h}$ and then rinsed for $30 \mathrm{~min}$ in $0.05 \mathrm{~m}$ Tris-buffered saline (TBS). After being incubated in $0.3 \%$ hydrogen peroxide $(15 \mathrm{~min}$ ) and rinsed in TBS (20 $\mathrm{min}$ ), sections were sequentially incubated in $2 \%$ normal goat serum with $0.3 \%$ Triton $\mathrm{X}-100(1 \mathrm{~h})$ followed by $2 \%$ normal goat serum and mouse NeuN monoclonal antibody (1:1000; Chemicon, Temecula, CA) with $0.3 \%$ Triton $\mathrm{X}-100$ and left overnight at $4^{\circ} \mathrm{C}$. The following day, slides were rinsed in TBS (20 min), incubated in $2 \%$ normal goat serum and biotin-conjugated goat anti-mouse IgG with $0.3 \%$ Triton X-100 (1 $\mathrm{h})$, and then rinsed in TBS $(20 \mathrm{~min})$. Slides were then incubated in avidin-biotin-peroxidase complex (Elite ABC kit; Vectastain; Vector Laboratories, Burlingame, CA) for $1 \mathrm{~h}$, rinsed in TBS (20 min), and incubated in TBS with $0.03 \%$ hydrogen peroxide and $0.025 \% 3,3^{\prime}$ diaminobenzidine $(3 \mathrm{~min})$. Finally, the slides were rinsed in TBS (20 $\mathrm{min}$ ), dehydrated sequentially in increasing concentrations of alcohol, and coverslipped.

Statistics. To examine whether the locomotor response to saline or cocaine $(7.5,15$, or $30 \mathrm{mg} / \mathrm{kg})$ varied as a function of lesion, a mixedmodel ANOVA was used, with time and lesion included in the model. Mixed-model ANOVA is especially appropriate for analyzing data with repeated measures, when correlations among the measurements are likely, and allows for greater flexibility in modeling time effects than other repeated-measures analyses (Gueorguieva and Krystal, 2004). A Satterthwaite approximation for the denominator degrees of freedom was used, producing decimal places in these values. Dose-effect functions were also examined with mixed-model ANOVA, with dose, lesion, and injection day (first and challenge) included in the model.
Influence of bilateral STN lesions on the acquisition of cocaine self-administration and progressive ratio performance for cocaine Subjects. Twenty-six male Sprague Dawley rats (Harlan) weighing 225$250 \mathrm{~g}$ were housed in the same conditions as described in experiment 1 , other than that the animals were kept on a $14 / 10 \mathrm{~h}$ reverse light/dark cycle (lights off at 7:00 A.M.).

Surgical procedures. After 1 week of housing, 15 rats were randomly chosen to receive bilateral subthalamic nucleus lesions, and the remaining 11 rats received vehicle alone $(0.1 \mathrm{M}$ PBS), using the same surgical procedures as in experiment 1 .

Twelve to $14 \mathrm{~d}$ after stereotaxic surgery, animals were implanted with intravenous catheters while under ketamine and xylazine anesthesia. Catheter construction and implantation were based on previously described procedures (Weeks, 1972; Crombag et al., 2000). Briefly, a silicone catheter was inserted into the right external jugular vein and was passed subcutaneously to exit the back of the animal, where it was connected to a pedestal constructed from a 22 gauge cannula connected to a piece of polyethylene mesh using dental cement. After surgery, catheters were flushed daily with $0.1 \mathrm{ml}$ of sterile saline containing gentamicin $(0.08 \mathrm{mg} / \mathrm{ml})$ to prevent occlusions and microbial buildup in the catheter. Rats were allowed to recover for a minimum of $5 \mathrm{~d}$ before experimental testing.

Apparatus. Behavioral testing was conducted in standard operant chambers (Med Associates, Georgia, VT) containing an acrylic hinged loading door, stainless-steel side panels, and an acrylic back panel $(22 \times$ $18 \times 13 \mathrm{~cm}$ ). The chambers were located in sound- and light-attenuating cabinets equipped with fans providing constant ventilation and low-level background noise. Two nose-poke holes containing a white cue light and a tone generator $(75 \mathrm{~dB})$ were located on one wall of the chamber $\sim 3 \mathrm{~cm}$ above the floor. Responding into one (active) nose-poke hole resulted in the simultaneous delivery of cocaine (or saline; see below) and a $5 \mathrm{~s}$ activation of the cue light and tone. Responses in the second (inactive) hole was recorded but had no programmed consequences.

Acquisition and progressive ratio. During the acquisition phase of the experiment, rats were allowed to nose poke to obtain an intravenous infusion of cocaine on a continuous [fixed ratio 1 (FR1)] schedule of reinforcement. Each session began with the illumination of the house light and activation of the nose-poke stimulus light and tone for $10 \mathrm{~s}$. After the initial $10 \mathrm{~s}$, responses in the active hole activated an infusion pump, delivering a single bolus infusion of cocaine over $2.8 \mathrm{~s}$, as well as a $5 \mathrm{~s}$ activation of the cue light and tone. During the $5 \mathrm{~s}$ when the cue light and tone were activated, nose pokes were recorded but were not reinforced (time-out period). At the end of each $1 \mathrm{~h}$ session, the house light was turned off and rats were returned to their home cages.

For the first $5 \mathrm{~d}$ of testing, responses in the active hole resulted in the administration of $0.3 \mathrm{mg} / \mathrm{kg}$ cocaine. Animals were then given $2 \mathrm{~d}$ off, followed by 5 more days of self-administration, during which responding in the active hole resulted in infusions of $0.4 \mathrm{mg} / \mathrm{kg}$ cocaine. After 2 more days off, rats were given an additional $5 \mathrm{~d}$ of training at $0.5 \mathrm{mg} / \mathrm{kg} /$ infusion of cocaine and then given 2 more days off.

Rats were then transferred to a PR schedule of reinforcement, in which infusions were contingent on an escalating number of responses required to receive cocaine using the following progression: $1,2,4,6,9,12,15,20$, 25, 32, 40, 50, 62 , 77, 95, 118, 145, 178, 219, 268, 328, 402, 492, 603 [based on Richardson and Roberts (1996)]. Rats received one cocaine dose (0.5 $\mathrm{mg} / \mathrm{kg}$ per infusion) for the first two consecutive PR sessions, and then the dose was decreased for the next two PR session and so on. The cocaine doses decreased from 0.5 to 0.3 to 0.15 to $0.0 \mathrm{mg} / \mathrm{kg}$ per infusion. A session was terminated when an animal failed to reach the criterion for the next infusion within an hour.

Catheters were screened for patency during the acquisition and progressive ratio components of the experiment before each time the dose of cocaine was changed. Catheter patency was examined by manually injecting $0.1 \mathrm{ml}$ of the short-acting barbiturate sodium thiopenthal (20 $\mathrm{mg} / \mathrm{ml}$, i.v. in sterile water). Rats that became ataxic within $5 \mathrm{~s}$ were considered to have patent catheters. If a rat did not become ataxic, the data for that animal from the preceding dose was not included in the analysis, and the animal was not further tested on self-administration. Only two catheters lost patency during the $23 \mathrm{~d}$ of testing. 

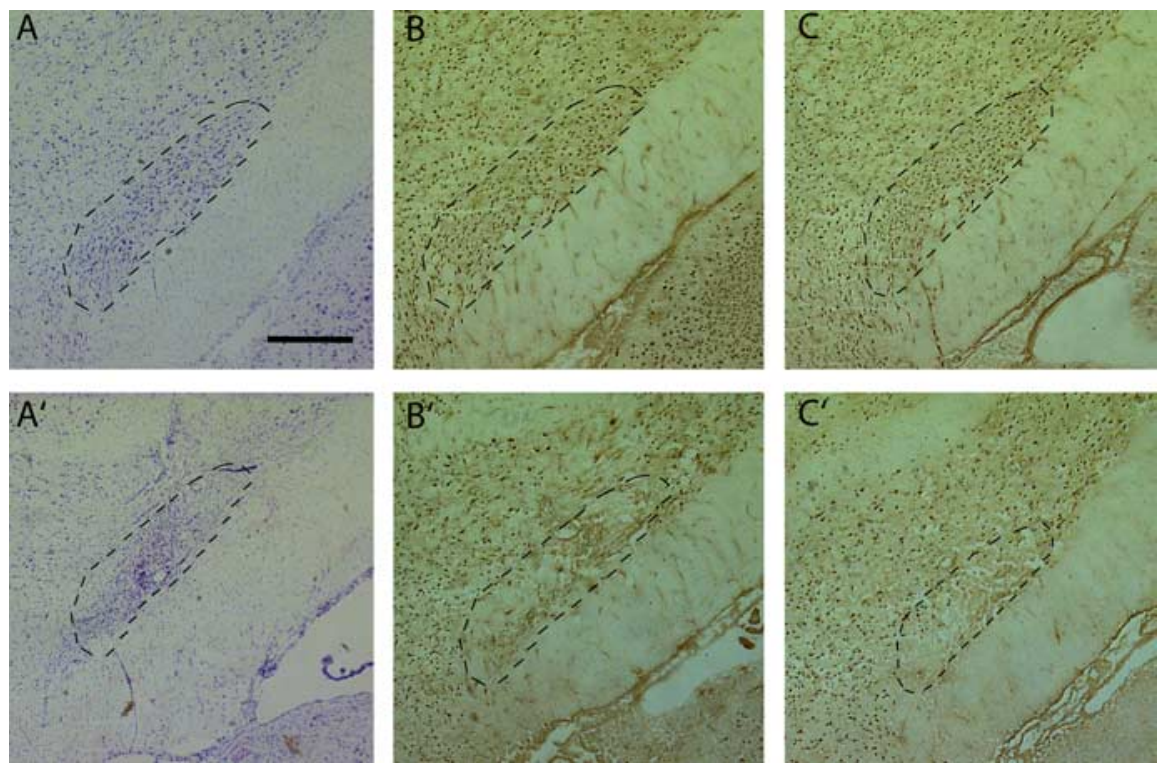

Figure 1. Representative photomicrograph of cresyl violet- and NeuN-stained sections at the level of the STN in a sham contro animal $(\boldsymbol{A}-\boldsymbol{C})$ and in an animal with an STN lesion $\left(\boldsymbol{A}^{\prime}-\boldsymbol{C}^{\prime}\right)$. Gliosis, cell loss, and shrinkage of the STN are apparent in the cresyl violet-stained section of the lesioned animal $\left(\boldsymbol{A}^{\prime}\right)$. NeuN staining also reveals cell loss in the rostral and caudal STN of the lesioned animal ( $\boldsymbol{B}^{\prime}, \boldsymbol{C}^{\prime}$; sections $\sim 300 \mu \mathrm{m}$ apart at 3.8 and $4.1 \mathrm{~mm}$ posterior to bregma). The dashed lines indicate the boundaries of the STN. Scale bar, $250 \mu \mathrm{m}$.

Verification of the lesion. After behavioral testing, verification of the lesion was performed as in experiment 1.

Statistics. To examine whether STN lesions influence the acquisition of cocaine self-administration, the data from each dose was analyzed separately using mixed-model ANOVA, with day and lesion included in the model. To examine whether STN lesions influence motivation for Cocaine under a progressive ratio schedule, mixed-model ANOVA was used with day and lesion included in the model. Only the days in which drug was available (i.e., not saline) were included in this analysis. To examine whether STN lesions enhanced nose-poke responding regardless of cocaine availability, a mixed-model ANOVA was conducted with day and lesion included in the model, and only the days in which saline was available were included in the analysis. Finally, to examine whether STN lesions indiscriminately increased responding as a result of the general increase in behavior produced by cocaine, inactive nose pokes during acquisition and progressive ratio performance were examined with the same factors included in the mixed-model ANOVAs as were used to examine total cocaine infusions.

Influence of bilateral STN lesions on cocaine-induced $c$-fos $m R N A$ expression and cocaine-induced psychomotor activation

Subjects. Thirty-eight male Sprague Dawley rats (Harlan) weighing 225$250 \mathrm{~g}$ were housed in the same conditions as animals from experiment 1.

Surgical procedures. After 1 week of housing, 24 rats were randomly chosen to receive bilateral subthalamic nucleus lesions, and the remaining 14 rats received vehicle alone $(0.1 \mathrm{M}$ PBS), using the same surgical procedures as in experiment 1.

Testing procedures. Twelve to $14 \mathrm{~d}$ after surgery, animals were transferred to the same locomotor test cages as used in experiment 1 . After a 60 min habituation period, animals were given either saline or cocaine (15 $\mathrm{mg} / \mathrm{kg}$, i.p.), and locomotor behavior was recorded. The $15 \mathrm{mg} / \mathrm{kg}$ dose of cocaine was chosen on the basis of the results from experiment 1 , which indicated that the acute psychomotor response to this dose varied as a result of STN lesion. Fifty minutes after the injection, the animals were decapitated, and their brains were removed, frozen in isopentane on dry ice, and stored at $-70^{\circ} \mathrm{C}$.

In situ hybridization. Brains were sectioned using a cryostat, and 16 $\mu \mathrm{m}$ coronal sections were thaw-mounted on to Superfost/Plus slides and stored at $-70^{\circ} \mathrm{C}$. In situ hybridization methods were as described previously (Uslaner et al., 2001b). A section from the medial prefrontal cortex
(2.7 $\mathrm{mm}$ anterior to bregma), two sections from the nucleus accumbens $(2.2$ and $1.7 \mathrm{~mm}$ anterior to bregma), and three sections from the caudate-putamen ( 1.7 and $0.2 \mathrm{~mm}$ anterior to bregma and $0.8 \mathrm{~mm}$ posterior to bregma) from each animal were processed for in situ hybridization using ${ }^{35} \mathrm{~S}-\mathrm{UTP}$ - and ${ }^{35} \mathrm{~S}-\mathrm{CTP}$ labeled riboprobes for c-fos mRNA (680-mer; courtesy of Dr. T. Curran, St. Jude Children's Research Hospital, Memphis, TN). After processing, sections were exposed to x-ray film (Kodak BioMax MR; Eastman Kodak, Rochester, NY) for $2 \mathrm{~d}$.

Quantification. Sections were quantified as described previously (Badiani et al., 1998; Uslaner et al., 2001b). Briefly, brain images were captured with a Sony (Tokyo, Japan) CCD camera from the $\mathrm{x}$-ray film, and semiquantitative analysis was performed on the digitized autoradiograms using NIH Image software. Pixels were counted when the optical density values were at least 3.5 SDs above background value (obtained from corpus callosum). Thus, the data are represented as relative integrated density in arbitrary units, which reflects both signa intensity and the number of pixels above background divided by total area (Badiani et al. 1998; Day et al., 2001; Uslaner et al., 2001b).

The medial prefrontal cortex was divided into cingulate 1 , prelimbic, and infralimbic regions according to Paxinos and Watson (1982), and each region was analyzed separately. The caudate-putamen was subdivided according to the anatomical projections of its predominant cortical inputs, as described by Willuhn et al. (2003). The nucleus accumbens was divided into core and shell subregions, according to Paxinos and Watson (1982), and the shell was further subdivided into a ventral and medial region, based on their different efferents and afferents (Zahm and Brog, 1992; Yano and Steiner, 2005).

Verification of lesion. Sections from the STN were stained with cresyl violet to examine the extent of the lesion, as in experiment 1 .

Statistics. To investigate whether the locomotor response during habituation or drug administration varied as a function of lesion, mixedmodel ANOVA was used with lesion and time included in the model.

The levels of c-fos mRNA expression in subregions of the cortex, caudate-putamen, and nucleus accumbens were analyzed by making three sets of comparisons. (1) To determine whether cocaine treatment enhanced c-fos mRNA expression above saline, one-way ANOVA was used with treatment as the factor. Lesioned and control animals were analyzed separately. (2) To determine whether bilateral STN lesions influence basal levels of c-fos mRNA expression, one-way ANOVA was used with lesion as the factor, and only saline-treated animals were included in the analysis. (3) To determine whether cocaine-induced c-fos mRNA expression differed as a function of lesion, one-way ANOVA was used with lesion as a factor, and only cocaine-treated animals were included in the analysis.

\section{Results \\ Influence of bilateral STN lesions on cocaine-induced psychomotor activation}

\section{Histology}

The size of the lesion was verified by assessing the extent of cell loss and gliosis in the STN and surrounding areas. Of the 22 rats injected with ibotenic acid, 18 showed either complete or almost complete bilateral damage to the STN. Two animals showed cell loss unilaterally, and two animals had lesions dorsal to the STN, mainly confined to the zona incerta. These four animals were not included in the data analysis, but visual examination of the psy- 


\section{First Injections}
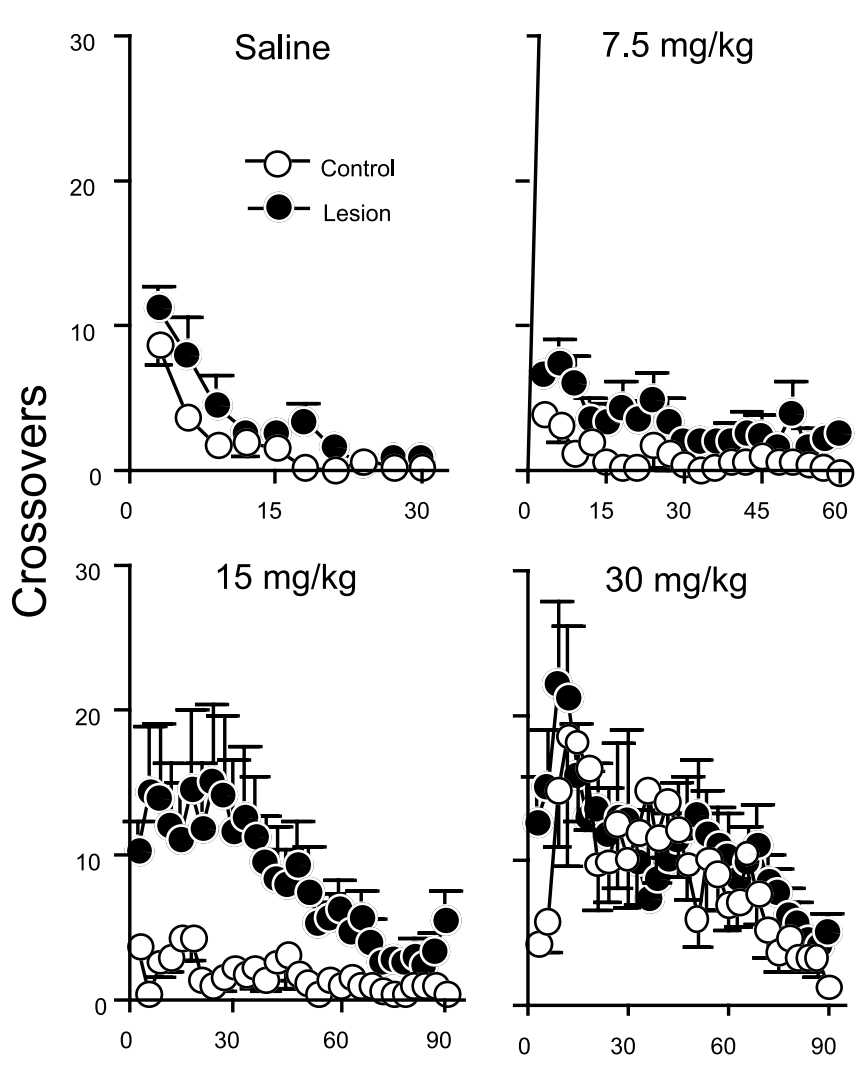

\section{Time after injection (min)}

Figure 2. The time course of the psychomotor activating response produced by the first injections of saline or cocaine $(7.5,15$, or $30 \mathrm{mg} / \mathrm{kg})$ as a function of STN lesion. The psychomotor-activating response to 7.5 and $15 \mathrm{mg} / \mathrm{kg}$ cocaine was greater in STN-lesioned animals (filled circles) compared with sham controls (open circles). Error bars represent SEM.

chomotor activity data from these animals revealed that they were similar to the sham group.

Figure 1 shows a photomicrograph of representative cresyl violet- and NeuN-stained sections, illustrating the extent of the lesions. Cell loss was mainly restricted to the subthalamic nucleus, with little damage extending dorsally or medially into the zona incerta. Furthermore, the lesion was apparent throughout the extent of the STN, as indicated by cell loss in both the rostral and caudal STN (Fig. 1, compare $B^{\prime}, C^{\prime}$ and $B, C$ ).

\section{Locomotor response to cocaine in animals with bilateral}

STN lesions

The locomotor response to the injections of saline and cocaine on the first test day is shown in Figure 2. STN-lesioned animals did not differ from sham controls in their response to saline (main effect of lesion, $F_{(1,101.17)}=1.16, p=0.28$; lesion-by-time, $\left.F_{(1,102.99)}=0.075, p=0.39\right)$. In contrast, animals with bilateral STN lesions showed significantly greater cocaine-induced psychomotor activity to $7.5 \mathrm{mg} / \mathrm{kg}$ cocaine (main effect of lesion, $F_{(1,100.62)}=4.03, p=0.047$; lesion-by-time interaction, $F_{(1,117.36)}=$ $0.26, p=0.61$ ) and $15 \mathrm{mg} / \mathrm{kg}$ cocaine (main effect of lesion, $F_{(1,83.26)}=4.48, p=0.037$; lesion-by-time interaction, $F_{(1,119.05)}=$ $0.55, p=0.46)$. There was no effect of the STN lesion on the response to $30 \mathrm{mg} / \mathrm{kg}$ cocaine (main effect of lesion, $F_{(1,96.14)}=$ $0.88, p=0.35$; lesion-by-time, $\left.F_{(1,115.96)}=0.15, p=0.70\right)$.

\section{Challenge Injections}

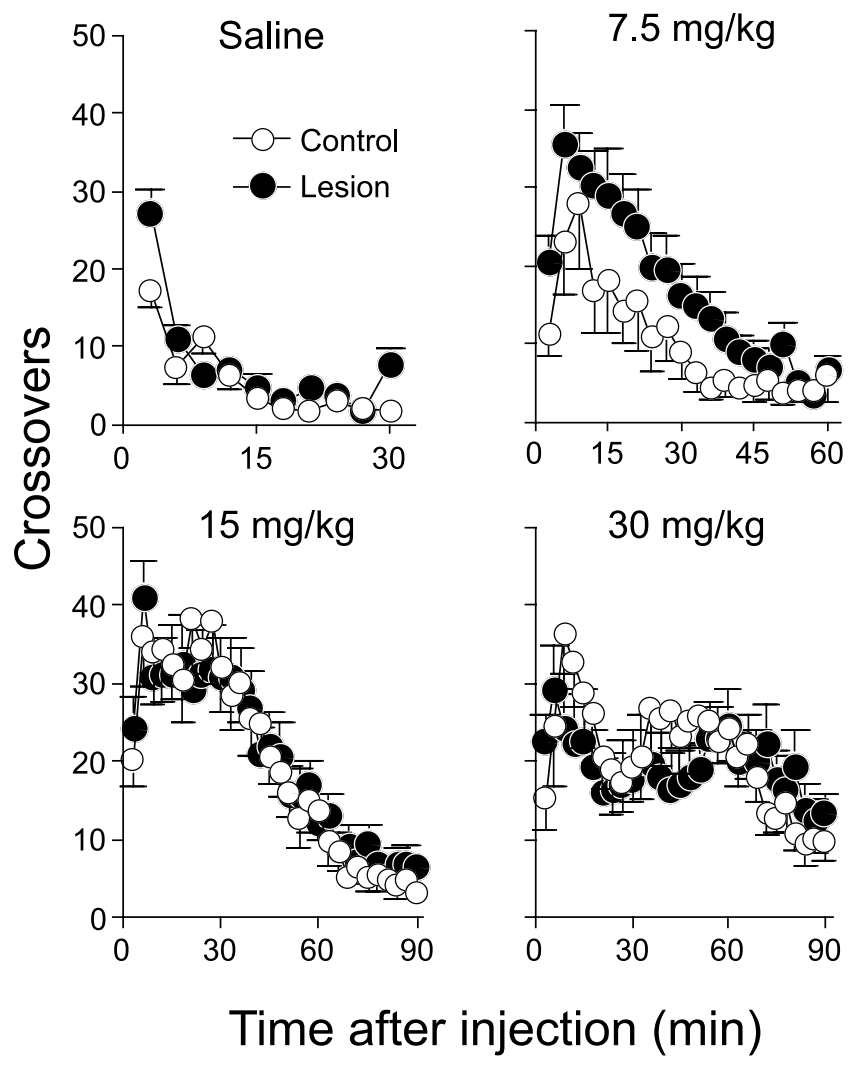

Figure 3. The time course of the psychomotor-activating response to the challenge injections of saline or cocaine as a function of STN lesion. The response to the $7.5 \mathrm{mg} / \mathrm{kg}$ challenge injection was greater in STN-lesioned animals (filled circles) as opposed to sham controls (open circles). Error bars represent SEM.

The effect of cocaine on the challenge test day is shown in Figure 3. There was no difference between animals with STN lesions and sham controls in the response to saline (main effect of lesion, $F_{(1,68.38)}=0.70, p=0.41$; lesion-by-time, $F_{(1,69.22)}=0.36$, $p=0.55)$ or to 15 or $30 \mathrm{mg} / \mathrm{kg}$ cocaine $(15 \mathrm{mg} / \mathrm{kg}$ : main effect of lesion, $F_{(1,91.58)}=0.00, p=0.99$; lesion-by-time, $F_{(1,111.25)}=$ $0.04, p=0.84 ; 30 \mathrm{mg} / \mathrm{kg}$ : main effect of lesion, $F_{(1,85.96)}=0.01$, $p=0.94$; lesion-by-time, $\left.F_{(1,115.75)}=0.03, p=0.87\right)$. However, animals with bilateral STN lesions showed a greater psychomotor response to $7.5 \mathrm{mg} / \mathrm{kg}$ cocaine (main effect of lesion, $F_{(1,84.28)}=$ $4.64, p=0.034$; lesion-by-time interaction, $F_{(1,109.10)}=1.43, p=$ $0.24)$.

The dose-effect curves for the first and last injections are shown in Figure 4. Both the sham controls and animals with STN lesions showed a greater response to cocaine on the last day of treatment, compared with the first day (i.e., both group sensitized) as well as a greater response to the larger doses of cocaine (sham: main effect of day, $F_{(1,25.12)}=58.50, p<0.001$; dose, $F_{(3,47.28)}=7.31, p<0.001$; lesion: main effect of day, $F_{(1,89.41)}=$ $77.73, p<0.001$; dose, $\left.F_{(3,96.76)}=4.19, p<0.01\right)$. Furthermore, for both sham controls and animals with STN lesions, there was a significant interaction between the day of drug administration and the dose administered (sham: day-by-dose interaction, $F_{(3,47.76)}=4.63, p<0.01$; lesion: day-by-dose interaction, $\left.F_{(3,107.84)}=6.12, p<0.002\right)$. Unpaired $t$ tests revealed that the sham controls showed a greater response to the challenge injection for all the doses administered compared with response on 


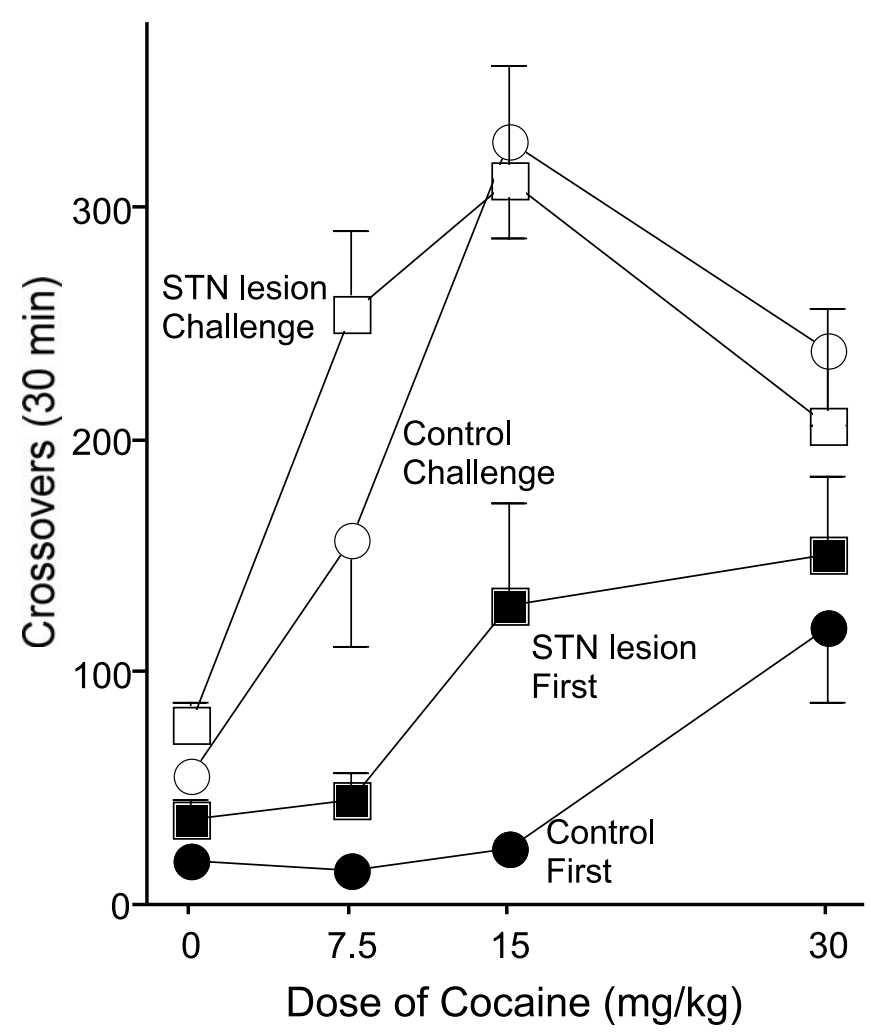

Figure 4. The dose-response curve of the first cocaine injection (filled symbols) and the challenge cocaine injection (open symbols) in sham controls (circles) and STN-lesioned animals (squares). Error bars represent SEM.

the first day (all $t$ tests, $p$ values $<0.01$ ), and STN-lesioned animals also showed a greater response on the last day, relative to the first day, for all doses except $30 \mathrm{mg} / \mathrm{kg}$ ( $p$ values $<0.008$ ). Finally, when dose, lesion, and day were included in the model, there was no interaction between these factors, indicating that STN lesions did not influence the development of behavioral sensitization $\left(\right.$ day-by-lesion-by-dose interaction; $\left.F_{(3,159.30)}=1.94 ; p=0.125\right)$.

\section{Influence of bilateral STN lesions on the acquisition of cocaine self-administration and progressive ratio performance for cocaine}

\section{Histology}

The size of the lesion was verified in the same manner as in experiment 1 . Of the 15 rats injected with ibotenic acid, 14 showed either complete or almost complete bilateral damage to the STN. One animal showed cell loss unilaterally and was excluded from the analysis.

\section{Influence of bilateral STN lesions on the acquisition of} cocaine self-administration

Figure 5 shows the data from the acquisition phase of the experiment. As can be seen, STN-lesioned animals showed greater responding for $0.3 \mathrm{mg} / \mathrm{kg}$ cocaine (main effect of lesion, $F_{(1,53.98)}=$ $4.11, p=0.045$; lesion-by-day interaction, $F_{(1,104.11)}=1.51, p=$ 0.22 ), whereas there was no difference between the lesion group and the sham controls for $0.4 \mathrm{mg} / \mathrm{kg}$ cocaine (main effect of lesion, $F_{(1,100.20)}=0.25, p=0.62$; lesion-by-day interaction, $F_{(1,107.19)}=1.39, p=0.24$ ) or $0.5 \mathrm{mg} / \mathrm{kg}$ cocaine (main effect of lesion, $F_{(1,105.85)}=0.10, p=0.76$; lesion-by-day interaction, $\left.F_{(1,107.94)}=0.45, p=0.51\right)$. STN lesions had no effect on inactive
Acquisition
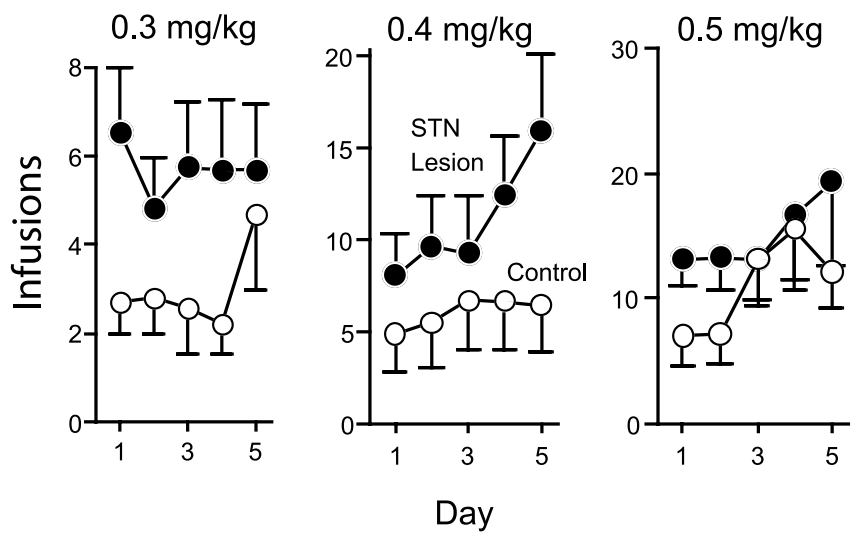

Figure 5. The acquisition of cocaine self-administration as a function of dose and STN lesion. At each dose, animals were given $5 \mathrm{~d}$ of self-administration on an FR1 schedule. STN-lesioned animals (filled circles) took a greater number of infusions when $0.3 \mathrm{mg} / \mathrm{kg}$ cocaine was available compared with sham controls (open circles). Error bars represent SEM.

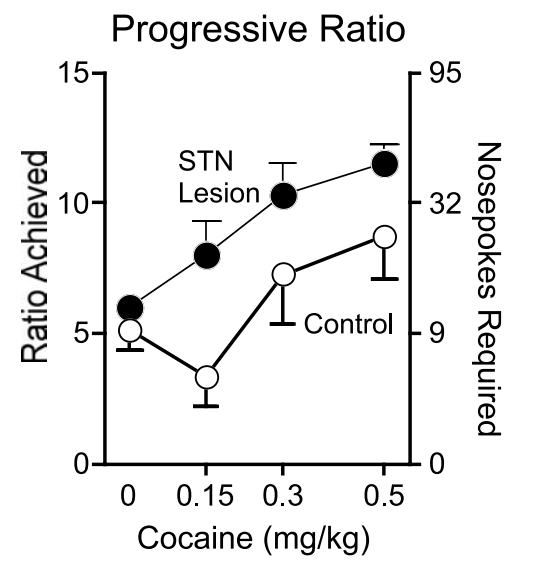

Figure 6. Progressive ratio performance as a function of dose and STN lesion. The STNlesioned animals (filled circles) reached a higher breakpoint than sham controls (open circles) when cocaine was available, regardless of dose. Error bars represent SEM.

nose pokes for any of the doses examined (main effect of lesion and lesion-by-day interaction for all doses, $p$ values $>0.05$ ).

Influence of bilateral STN lesions on motivation for cocaine under a progressive ratio schedule

Figure 6 shows the progressive ratio data from STN-lesioned animals and sham controls as a function of dose. As can be seen, STN-lesioned animals reached a significantly higher breakpoint when responding for cocaine (as indicated by the number of infusions taken) compared with sham controls (main effect of lesion, $F_{(1,23.18)}=5.76, p=0.025$; lesion-by-day interaction, $\left.F_{(5,87.89)}=0.87, p=0.51\right)$. This difference was not merely the result of STN-lesioned animals being generally hyperactive, because they did not respond more than sham controls when only saline was available (main effect of lesion; $F_{(1,17)}=0.93 ; p=$ $0.35)$. In addition, STN lesions did not increase indiscriminate responding during the progressive ratio performance, because the number of inactive nose pokes did not differ between animals with STN lesions and sham controls when either cocaine or saline was available ( $p$ values $>0.05$ ). 


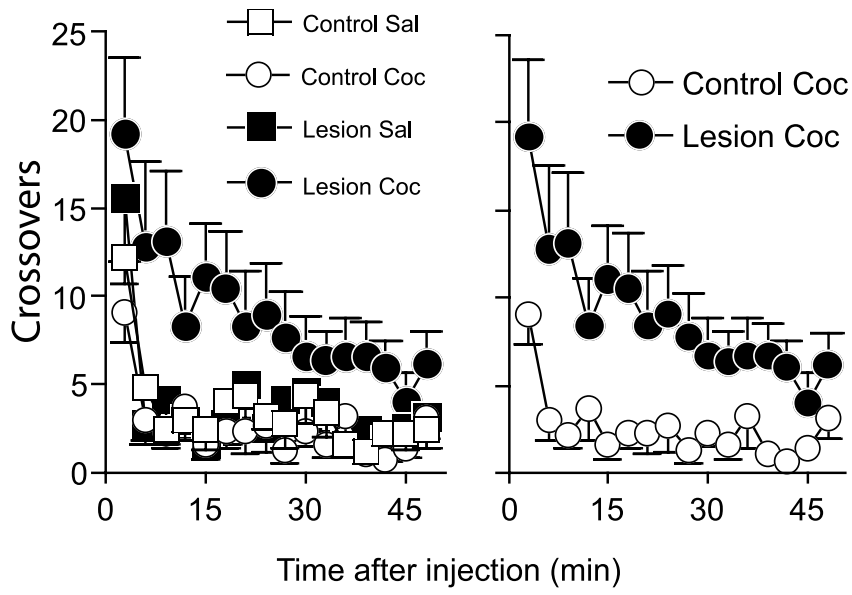

Figure 7. The psychomotor-activating response of saline (Sal; squares) or $15 \mathrm{mg} / \mathrm{kg}$ cocaine (Coc; circles) in sham controls (open symbols) and STN-lesioned animals (filled symbols). The graph to the left includes all four groups, and for ease of comparison, the graph to the right only includes the cocaine-treated animals. The STN-lesioned animals (filled circles) showed an enhanced psychomotor-activating response to $15 \mathrm{mg} / \mathrm{kg}$ cocaine compared with sham controls (open circles). Error bars represent SEM.

Influence of bilateral STN lesions on cocaine-induced c-fos mRNA expression and cocaine-induced psychomotor activation Histology

The size of the lesion was verified in the same manner as in experiment 1 . Of the 24 rats injected with ibotenic acid, 19 showed either complete or almost complete bilateral damage to the STN. One animal showed cell loss unilaterally, and four animals had lesions outside the STN. These five animals were not included in the data analysis, but visual examination of their data revealed that the cocaine-induced psychomotor response and c-fos mRNA expression was similar to sham controls.

\section{Locomotor response to cocaine in animals with bilateral}

STN lesions

The locomotor response to saline and cocaine $(15 \mathrm{mg} / \mathrm{kg})$ is shown in Figure 7. With lesion, drug, and time in the model, mixed-model ANOVA revealed a main effect of lesion $\left(F_{(1,92.99)}=\right.$ $5.07 ; p=0.027)$ and time $\left(F_{(1,115.61)}=16.53 ; p<0.001\right)$ but no main effect of drug $\left(F_{(1,92.99)}=0.64 ; p=0.42\right)$ and no interaction between drug, time, and lesion $\left(F_{(1,115.61)}=0.57 ; p=0.45\right)$. The main effect of lesion was attributable to the greater psychomotor response to cocaine, because there was a main effect of lesion when only the cocaine-treated animals were included in the analysis (main effect of lesion, $F_{(1,68.39)}=10.10, p=0.002$; lesion-bytime, $\left.F_{(1,85.84)}=2.18, p=0.14\right)$ but not when only the salinetreated animals were included in the analysis (main effect of lesion, $F_{(1,26.11)}=0.19, p=0.67$; lesion-by-time, $F_{(1,28.54)}=0.04$, $p=0.85)$.

The effects of bilateral STN lesions on cocaine-induced $c$-fos expression

Cocaine enhanced c-fos mRNA expression to a greater extent than saline in almost all portions of the caudate-putamen that were examined. Specifically, in sham controls receiving cocaine, c-fos mRNA expression was enhanced in all subregions of the $\mathrm{CPu}$ at 1.7 and $0.2 \mathrm{~mm}$ anterior to bregma (one-way ANOVA with drug as factor; $p$ values $<0.05$ in each subregion), but at 0.8 $\mathrm{mm}$ posterior to bregma, cocaine significantly increased $c$-fos expression in the dorsal $\mathrm{CPu}(p=0.035)$ but not in the medial, dorsolateral, ventrolateral, ventral, or central $\mathrm{CPu}$ (all $p$ values $>$ 0.05). In animals with bilateral STN lesions, cocaine enhanced

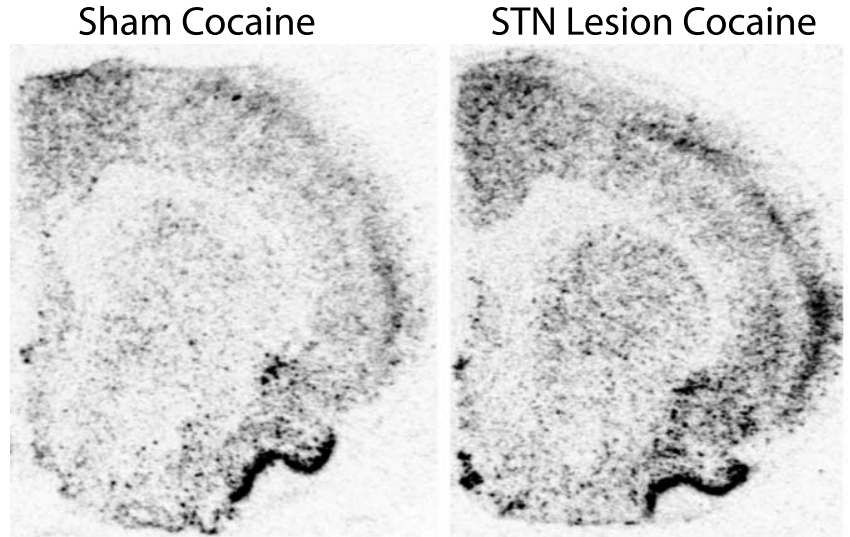

Figure 8. Representative autoradiographs at $\sim 1.7 \mathrm{~mm}$ anterior to bregma from cocainetreated sham controls and animals with an STN lesion. Cocaine increased c-fos expression to a greater extent in STN-lesioned animals, relative to sham controls, in several specific regions of the caudate-putamen and nucleus accumbens (see Results and Fig. 9 for details).

\section{Caudate Putamen}

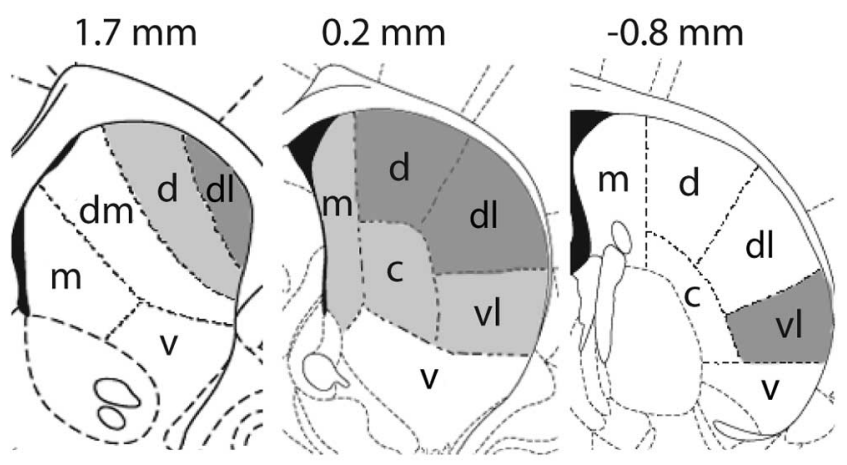

\section{Nucleus Accumbens}

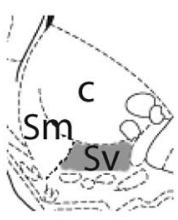

$2.2 \mathrm{~mm}$

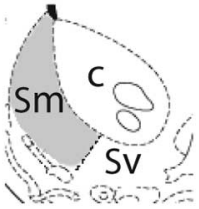

$1.7 \mathrm{~mm}$
Figure 9. Cocaine-induced c-fos mRNA expression in the caudate-putamen and nucleus accumbens in sham controls versus STN-lesioned animals. Dark shaded regions indicate that STN-lesioned animals showed significantly greater cocaine-induced c-fos mRNA expression relative to sham controls $(p<0.05)$. Lightly shaded regions indicate that STN-lesioned animals showed a trend toward significantly greater cocaine-induced $c-$ fos mRNA expression, relative to sham controls $(p<0.10)$. $m$, Medial; $v$, ventral; dm, dorsomedial; $d$, dorsal; $d$ l, dorsolateral; vl, ventrolateral; c, central; $C$, core; Sm, medial shell; Sv, ventral shell.

c-fos expression in every subregion of the CPu examined (all $p$ values $<0.05)$.

The ability of cocaine to enhance c-fos mRNA expression in several regions of the $\mathrm{CPu}$ was greater in STN-lesioned animals compared with sham controls (Figs. 8, 9). Specifically, STNlesioned animals showed significantly greater cocaine-induced c-fos mRNA expression in the dorsolateral $\mathrm{CPu}$ at $1.7 \mathrm{~mm}$ anterior to bregma, in the dorsolateral and dorsal $\mathrm{CPu}$ at $0.2 \mathrm{~mm}$ anterior to bregma, and in the ventrolateral $\mathrm{CPu}$ at $0.8 \mathrm{~mm}$ posterior to bregma (one-way ANOVA with lesion as a factor; $p$ val- 
ues $<0.05)$. Furthermore, there was a trend for a significant increase in c-fos mRNA expression in lesioned animals receiving cocaine, compared with sham controls, in the dorsal $\mathrm{CPu}$ at 1.7 $\mathrm{mm}$ anterior to bregma and in the medial, central, and ventrolateral $\mathrm{CPu}$ at $0.2 \mathrm{~mm}$ anterior to bregma (all $p$ values $<0.1$ ). The increased cocaine-induced c-fos mRNA expression in the CPu in STN-lesioned animals was not simply caused by an influence of STN lesions on basal levels of c-fos expression, because levels of $\mathrm{c}$-fos mRNA expression did not differ in any region of the $\mathrm{CPu}$ in STN-lesioned animals given saline compared with sham controls administered saline.

In sham controls, cocaine failed to significantly enhance c-fos mRNA expression in any portion of the nucleus accumbens that was analyzed ( $p$ values $>0.05$ for the core, medial, and ventral shell at 2.2 and $1.7 \mathrm{~mm}$ anterior to bregma). In contrast, cocaine significantly enhanced c-fos mRNA expression in the core and both the medial and ventral shell at $2.2 \mathrm{~mm}$ anterior to bregma, as well as in the medial shell at $1.7 \mathrm{~mm}$ anterior to bregma (all $p$ values $<0.04)$.

Furthermore, relative to sham controls, STN-lesioned animals showed significantly greater cocaine-induced c-fos mRNA expression in the ventral shell at $2.2 \mathrm{~mm}$ anterior to bregma (one-way ANOVA with lesion as a factor; $p=0.045$ ) (Figs. 8, 9) and a trend for a significant effect in the medial shell at $1.7 \mathrm{~mm}$ anterior to bregma ( $p=0.075)$. This effect was not caused by an influence of STN lesions on basal levels of c-fos mRNA expression, because saline-treated STN lesioned animals did not differ from sham controls receiving saline in any region of the nucleus accumbens examined.

In the medial prefrontal cortex, cocaine enhanced c-fos mRNA expression in both sham controls and STN-lesioned animals in the prelimbic region $(p$ values $<0.05$ ) but failed to significantly alter levels of c-fos expression in Cg 1 or the infralimbic region $(p>0.05)$. This effect was not modulated by STN lesion (all $p$ values $>0.05$ ).

\section{Discussion}

We report four major findings. First, STN lesions produced a dose-dependent increase in cocaine-induced psychomotor activation. This was apparent the first time animals received drug and persisted after repeated treatment. Second, STN lesions facilitated the acquisition of self-administration to a low dose of cocaine. Third, STN lesions enhanced motivation for cocaine (as indicated by higher breakpoints when tested using a progressive ratio schedule). Fourth, STN lesions increased cocaine-induced c-fos mRNA expression in the CPu and NAcc. These effects were not attributable to motor abnormalities or general increases in arousal, because STN lesions did not influence the locomotor response to saline, self-administration when saline was available, or inactive nose pokes. Thus, these results indicate that STN lesions enhance the behavioral and neurobiological effects of cocaine and, by inference, suggest that the intact STN inhibits the psychomotor activating and incentive motivational effects of cocaine, perhaps by modulating its ability to engage the NAcc and $\mathrm{CPu}$.

Our findings are consistent with evidence indicating that STN lesions increase motivation as well as the response to drugs that enhance dopaminergic transmission. For example, Baunez and colleagues reported that bilateral STN lesions enhance motivation for food, as measured by progressive ratio performance and conditioned place preference (Baunez et al., 2002, 2005). Furthermore, HFS of the STN, which is thought to mimic ablation of the STN by inducing depolarization block (Benazzouz et al.,
1993, 1995, 2000; Lozano et al., 2002) (but see Garcia et al., 2005), enhances motivation and decreases apathy and also increases the therapeutic potency of the dopamine-enhancing drug L-3,4dihydroxyphenylalanine (L-DOPA) in patients with Parkinson's disease (Limousin et al., 1998; Houeto et al., 2002; Funkiewiez et al., 2003; Ashkan et al., 2004).

Although the mechanisms by which STN lesions increase the behavioral and neurobiological effects of cocaine are unknown, we speculate that dopaminergic neurotransmission is involved. Dopaminergic antagonists and lesions of dopamine-containing cell bodies attenuate stimulant-induced psychomotor activation, self-administration, and c-fos expression (Schlechter and Butcher, 1972; Wilson and Schuster, 1972; Hollister et al., 1974; Roberts et al., 1977, 1989; Graybiel et al., 1990; Bhat and Baraban, 1993; Cenci and Bjorklund, 1994). Furthermore, HFS of the STN increases the therapeutic efficacy of L-DOPA in patients with Parkinson's disease. Although L-DOPA enhances extracellular dopamine by different mechanisms than cocaine, it is believed to produce its therapeutic effect by increasing extracellular dopamine in the striatum. Thus, we hypothesize that STN lesions increase the psychomotor-activating and incentive motivational effects of cocaine and cocaine-induced c-fos expression in the striatum (and perhaps also the therapeutic effects of L-DOPA) by enhancing dopaminergic neurotransmission in the striatum. Indeed, inhibition of the STN with muscimol, as well as disconnection of the STN and substantia nigra, have been shown to enhance the firing rate of dopamine-containing neurons, presumably by removing STN-mediated activation of the inhibitory GABAergic projections from the substantia nigra pars reticulata onto dopamine-containing cells (Smith and Grace, 1992).

At first glance, the current findings appear to be at odds with our previous reports that cocaine-induced c-fos expression in the STN is sensitized after cocaine pretreatment (Uslaner et al., 2003b), and that cocaine- and amphetamine-induced c-fos expression in the STN is enhanced under conditions that produce robust psychomotor activation (Uslaner et al., 2001a, 2003a). Given the reported relationship between c-fos expression and neuronal firing, our previous findings prompted us to speculate that activation of the STN may be related to the psychomotoractivating and the reinforcing effects of these drugs.

However, we believe that our current and past findings can be reconciled a number of ways. First, c-fos mRNA expression and neuronal activity, although generally correlated, need not always be (Sgambato et al., 1997). Indeed, c-fos mRNA expression and the firing rate of STN neurons have been found to vary in opposite directions after dopaminergic manipulations (Hassani and Feger, 1999). Furthermore, some STN neurons exhibit an initial decrease followed by a delayed increase in firing in response to iontophoretically applied dopamine (Campbell et al., 1985). Thus, stimulant-induced c-fos expression in the STN may reflect neuronal inhibition, or a subtle switch in the firing mode of STN neurons that may be involved in the psychomotor-activating effects of psychostimulants.

Alternatively, stimulant-induced activation of the STN may not be directly related to the psychomotor-activating effects of these drugs but rather may engage an inhibitory process that increases under conditions in which the behavioral and reinforcing effects of drugs of abuse are also increased. This inhibitory process may serve to dampen responding to the incentive motivational effects of drugs of abuse. Indeed, one perplexing issue in the self-administration literature is that well trained animals can tightly regulate the amount of drug they consume. For example, 
increasing the dose of drug available to animals on a fixed ratio schedule is met with a decrease in response rate (Pickens and Harris, 1968). This is not solely the result of the aversive effects of high doses. Thus, even when drug is directly self-administered into the nucleus accumbens, animals self-regulate their intake (Hoebel et al., 1983). These findings are difficult to explain purely in terms of the incentive motivational properties of drugs of abuse, leading some to speculate that drugs of abuse simultaneously activate an inhibitory process that decreases operant responding (Ettenberg and Geist, 1993; Kiyatkin and Stein, 1995; Winstanley et al., 2003). We posit that this inhibitory process is mediated, at least in part, by the STN. Thus, as dose is increased, STN engagement is also increased, restraining the animal from consuming more drug. However, when the STN is damaged, this constraint is at least partially removed, leading to greater drug consumption. We speculate that attenuation of this inhibitory process may render an individual especially susceptible to the reinforcing effects of drugs or exacerbate drug addiction by leaving only the incentive motivational process intact, unchecked by the inhibitory process (Jentsch and Taylor, 1999). Indeed, STN lesions have been shown to decrease response inhibition and enhance impulsivity for a food reward (Baunez and Robbins, 1997; Phillips and Brown, 1999, 2000; Florio et al., 2001).

Finally, it is important to note that Baunez et al. (2005) recently reported that STN lesions enhance motivation for food, as measured by progressive ratio performance and conditioned place preference, but decrease motivation for cocaine. This was surprising to us, not only because of our current findings, but also because the incentive motivational processes for food and drugs are believed to be controlled by similar brain systems (Kelley and Berridge, 2002).

We are unsure what accounts for the discrepancy between the current findings and those of Baunez et al. (2005), but there are several possibilities. First, we used a lower dose of cocaine to examine progressive ratio performance, compared with Baunez et al. (2005). Specifically, we constructed a dose-effect curve in which the highest dose used was the equivalent of $\sim 150 \mu \mathrm{g}$ cocaine per infusion (exact amount depending on the weight of the animal), whereas Baunez et al. (2005) used only a single dose of $250 \mu \mathrm{g}$ cocaine. Given that the psychomotor-activating effects of cocaine are enhanced in animals with STN lesions, it is possible that the high dose used by Baunez et al. (2005) produced behavior that interfered with operant responding in STN-lesioned animals. In addition, Baunez et al. (2005) tested animals in the light period of the light/dark cycle and used a 20 s time out, whereas we tested in the dark period and used a $5 \mathrm{~s}$ time out. Such differences may be important because the context of drug administration can dramatically influence the ability of cocaine to engage the STN (Uslaner et al., 2001a, 2003a).

A second possibility is that the size of the STN lesions may have varied between studies. We used a higher concentration of ibotenic acid than Baunez et al. (2005) to ensure large, complete lesions. Indeed, we originally planned on using the same dose of ibotenic acid as Baunez et al. (2005), but pilot studies revealed that, at least with our surgical procedures, this dose produced smaller, partial lesions compared with what we were able to achieve with the dose used here. Thus, the different results reported by Baunez et al. (2005) may be the result of different lesion sizes. Partial lesions can alter the morphology and the sensitivity of nearby spared tissue to compensate for loss of function (Jenkins and Merzenich, 1987; Castro-Alamancos and Borrel, 1995; Nudo and Milliken, 1996; Nudo et al., 1996). This issue will need to be more fully explored in future studies.
In conclusion, our results indicate that STN lesions enhance the psychomotor-activating, reinforcing, and incentive motivational effects of cocaine and increase the ability of cocaine to engage the $\mathrm{CPu}$ and NAcc. We speculate, therefore, that the intact STN inhibits these effects of cocaine and its ability to engage the striatum. These findings add to the growing body of literature highlighting the role of the STN in motivational and other limbic-related processes and suggest that the STN may serve as a novel target for therapeutic drugs aimed at treating drug dependence.

\section{References}

Albin RL, Young AB, Penney JB (1989) The functional anatomy of basal ganglia disorders. Trends Neurosci 12:366-375.

Ashkan K, Wallace B, Bell BA, Benabid AL (2004) Deep brain stimulation of the subthalamic nucleus in Parkinson's disease 1993-2003: where are we 10 years on? Br J Neurosurg 18:19-34.

Badiani A, Oates MM, Day HE, Watson SJ, Akil H, Robinson TE (1998) Amphetamine-induced behavior, dopamine release, and c-fos mRNA expression: modulation by environmental novelty. J Neurosci 18:10579-10593.

Baunez C, Robbins TW (1997) Bilateral lesions of the subthalamic nucleus induce multiple deficits in an attentional task in rats. Eur J Neurosci 9:2086-2099.

Baunez C, Amalric M, Robbins TW (2002) Enhanced food-related motivation after bilateral lesions of the subthalamic nucleus. J Neurosci 22:562-568.

Baunez C, Dias C, Cador M, Amalric M (2005) The subthalamic nucleus exerts opposite control on cocaine and 'natural' rewards. Nat Neurosci 8:484-489.

Benazzouz A, Gross C, Feger J, Boraud T, Bioulac B (1993) Reversal of rigidity and improvement in motor performance by subthalamic highfrequency stimulation in MPTP-treated monkeys. Eur J Neurosci 5:382-389.

Benazzouz A, Piallat B, Pollak P, Benabid AL (1995) Responses of substantia nigra pars reticulata and globus pallidus complex to high frequency stimulation of the subthalamic nucleus in rats: electrophysiological data. Neurosci Lett 189:77-80.

Benazzouz A, Gao DM, Ni ZG, Piallat B, Bouali-Benazzouz R, Benabid AL (2000) Effect of high-frequency stimulation of the subthalamic nucleus on the neuronal activities of the substantia nigra pars reticulata and ventrolateral nucleus of the thalamus in the rat. Neuroscience 99:289-295.

Bhat RV, Baraban JM (1993) Activation of transcription factor genes in striatum by cocaine: role of both serotonin and dopamine systems. J Pharmacol Exp Ther 267:496-505.

Campbell GA, Eckardt MJ, Weight FF (1985) Dopaminergic mechanisms in subthalamic nucleus of rat: analysis using horseradish peroxidase and microiontophoresis. Brain Res 333:261-270.

Carelli RM, Wightman RM (2004) Functional microcircuitry in the accumbens underlying drug addiction: insights from real-time signaling during behavior. Curr Opin Neurobiol 14:763-768.

Castro-Alamancos MA, Borrel J (1995) Functional recovery of forelimb response capacity after forelimb primary motor cortex damage in the rat is due to the reorganization of adjacent areas of cortex. Neuroscience 68:793-805.

Cenci MA, Bjorklund A (1994) Transection of corticostriatal afferents abolishes the hyperexpression of Fos and counteracts the development of rotational overcompensation induced by intrastriatal dopamine-rich grafts when challenged with amphetamine. Brain Res 665:167-174.

Crombag HS, Badiani A, Maren S, Robinson TE (2000) The role of contextual versus discrete drug-associated cues in promoting the induction of psychomotor sensitization to intravenous amphetamine. Behav Brain Res 116:1-22.

Crossman AR (1990) A hypothesis on the pathophysiological mechanisms that underlie levodopa- or dopamine agonist-induced dyskinesia in Parkinson's disease: implications for future strategies in treatment. Mov Disord 5:100-108.

Day HE, Badiani A, Uslaner JM, Oates MM, Vittoz NM, Robinson TE, Watson Jr SJ, Akil H (2001) Environmental novelty differentially affects c-fos mRNA expression induced by amphetamine or cocaine in subre- 
gions of the bed nucleus of the stria terminalis and amygdala. J Neurosci 21:732-740.

Ettenberg A, Geist TD (1993) Qualitative and quantitative differences in the operant runway behavior of rats working for cocaine and heroin reinforcement. Pharmacol Biochem Behav 44:191-198.

Florio T, Capozzo A, Cellini R, Pizzuti G, Staderini EM, Scarnati E (2001) Unilateral lesions of the pedunculopontine nucleus do not alleviate subthalamic nucleus-mediated anticipatory responding in a delayed sensorimotor task in the rat. Behav Brain Res 126:93-103.

Funkiewiez A, Ardouin C, Krack P, Fraix V, Van Blercom N, Xie J, Moro E, Benabid AL, Pollak P (2003) Acute psychotropic effects of bilateral subthalamic nucleus stimulation and levodopa in Parkinson's disease. Mov Disord 18:524-530.

Garcia L, D'Alessandro G, Bioulac B, Hammond C (2005) High-frequency stimulation in Parkinson's disease: more or less? Trends Neurosci 28:209-216.

Graybiel AM, Moratalla R, Robertson HA (1990) Amphetamine and cocaine induce drug-specific activation of the $\mathrm{c}$-fos gene in striosomematrix compartments and limbic subdivisions of the striatum. Proc Natl Acad Sci USA 87:6912-6916.

Groenewegen HJ, Berendse HW (1990) Connections of the subthalamic nucleus with ventral striatopallidal parts of the basal ganglia in the rat. J Comp Neurol 294:607-622.

Gueorguieva R, Krystal JH (2004) Move over ANOVA: progress in analyzing repeated-measures data and its reflection in papers published in the Archives of General Psychiatry. Arch Gen Psychiatry 61:310-317.

Hassani OK, Feger J (1999) Effects of intrasubthalamic injection of dopamine receptor agonists on subthalamic neurons in normal and 6-hydroxydopamine-lesioned rats: an electrophysiological and c-Fos study. Neuroscience 92:533-543.

Hoebel BG, Monaco AP, Hernandez L, Aulisi EF, Stanley BG, Lenard L (1983) Self-injection of amphetamine directly into the brain. Psychopharmacology (Berl) 81:158-163.

Hollister AS, Breese GR, Cooper BR (1974) Comparison of tyrosine hydroxylase and dopamine-beta-hydroxylase inhibition with the effects of various 6-hydroxydopamine treatments on D-amphetamine induced motor activity. Psychopharmacologia 36:1-16.

Houeto JL, Mesnage V, Mallet L, Pillon B, Gargiulo M, du Moncel ST, Bonnet AM, Pidoux B, Dormont D, Cornu P, Agid Y (2002) Behavioural disorders, Parkinson's disease and subthalamic stimulation. J Neurol Neurosurg Psychiatry 72:701-707.

Jenkins WM, Merzenich MM (1987) Reorganization of neocortical representations after brain injury: a neurophysiological model of the bases of recovery from stroke. Prog Brain Res 71:249-266.

Jentsch JD, Taylor JR (1999) Impulsivity resulting from frontostriatal dysfunction in drug abuse: implications for the control of behavior by reward-related stimuli. Psychopharmacology (Berl) 146:373-390.

Kelley AE, Berridge KC (2002) The neuroscience of natural rewards: relevance to addictive drugs. J Neurosci 22:3306-3311.

Kita H, Kitai ST (1987) Efferent projections of the subthalamic nucleus in the rat: light and electron microscopic analysis with the PHA-L method. J Comp Neurol 260:435-452.

Kiyatkin EA, Stein EA (1995) Fluctuations in nucleus accumbens dopamine during cocaine self-administration behavior: an in vivo electrochemical study. Neuroscience 64:599-617.

Li Y, Acerbo MJ, Robinson TE (2004) The induction of behavioural sensitization is associated with cocaine-induced structural plasticity in the core (but not shell) of the nucleus accumbens. Eur J Neurosci 20:1647-1654.

Limousin P, Krack P, Pollak P, Benazzouz A, Ardouin C, Hoffmann D, Benabid AL (1998) Electrical stimulation of the subthalamic nucleus in advanced Parkinson's disease. N Engl J Med 339:1105-1111.

Lozano AM, Dostrovsky J, Chen R, Ashby P (2002) Deep brain stimulation for Parkinson's disease: disrupting the disruption. Lancet Neurol 1:225-231.

Maurice N, Deniau JM, Glowinski J, Thierry AM (1998) Relationships between the prefrontal cortex and the basal ganglia in the rat: physiology of the corticosubthalamic circuits. J Neurosci 18:9539-9546.

Nudo RJ, Milliken GW (1996) Reorganization of movement representations in primary motor cortex following focal ischemic infarcts in adult squirrel monkeys. J Neurophysiol 75:2144-2149.
Nudo RJ, Wise BM, SiFuentes F, Milliken GW (1996) Neural substrates for the effects of rehabilitative training on motor recovery after ischemic infarct [see comments]. Science 272:1791-1794.

Paxinos G, Watson C (1982) The rat brain in stereotaxic coordinates, Ed 2. San Diego: Academic.

Phillips JM, Brown VJ (1999) Reaction time performance following unilateral striatal dopamine depletion and lesions of the subthalamic nucleus in the rat. Eur J Neurosci 11:1003-1010.

Phillips JM, Brown VJ (2000) Anticipatory errors after unilateral lesions of the subthalamic nucleus in the rat: evidence for a failure of response inhibition. Behav Neurosci 114:150-157.

Pickens R, Harris WC (1968) Self-administration of D-amphetamine by rats. Psychopharmacologia 12:158-163.

Richardson NR, Roberts DC (1996) Progressive ratio schedules in drug selfadministration studies in rats: a method to evaluate reinforcing efficacy. J Neurosci Methods 66:1-11.

Roberts DC, Corcoran ME, Fibiger HC (1977) On the role of ascending catecholaminergic systems in intravenous self-administration of cocaine. Pharmacol Biochem Behav 6:615-620.

Roberts DC, Loh EA, Vickers G (1989) Self-administration of cocaine on a progressive ratio schedule in rats: dose-response relationship and effect of haloperidol pretreatment. Psychopharmacology 97:535-538.

Schlechter JM, Butcher LL (1972) Blockade by pimozide of (+)amphetamine-induced hyperkinesia in mice. J Pharm Pharmacol 24:408-409.

Schultz W (1997) Dopamine neurons and their role in reward mechanisms. Curr Opin Neurobiol 7:191-197.

Sgambato V, Abo V, Rogard M, Besson MJ, Deniau JM (1997) Effect of electrical stimulation of the cerebral cortex on the expression of the Fos protein in the basal ganglia. Neuroscience 81:93-112.

Smith ID, Grace AA (1992) Role of the subthalamic nucleus in the regulation of nigral dopamine neuron activity. Synapse 12:287-303.

Takeshita S, Kurisu K, Trop L, Arita K, Akimitsu T, Verhoeff NP (2005) Effect of subthalamic stimulation on mood state in Parkinson's disease: evaluation of previous facts and problems. Neurosurg Rev 28:179-186.

Uslaner J, Badiani A, Norton C, Day H, Watson S, Akil H, Robinson T (2001a) Amphetamine and cocaine induce different patterns of c-fos mRNA expression in the striatum and subthalamic nucleus depending on environmental context. Eur J Neurosci 13:1977-1983.

Uslaner J, Badiani A, Day HE, Watson SJ, Akil H, Robinson TE (2001b) Environmental context modulates the ability of cocaine and amphetamine to induce c-fos mRNA expression in the neocortex, caudate nucleus, and nucleus accumbens. Brain Res 920:106-116.

Uslaner JM, Norton CS, Watson SJ, Akil H, Robinson TE (2003a) Amphetamine-induced c-fos mRNA expression in the caudate-putamen and subthalamic nucleus: interactions between dose, environment, and neuronal phenotype. J Neurochem 85:105-114.

Uslaner JM, Crombag HS, Ferguson SM, Robinson TE (2003b) Cocaineinduced psychomotor activity is associated with its ability to induce c-fos mRNA expression in the subthalamic nucleus: effects of dose and repeated treatment. Eur J Neurosci 17:2180-2186.

Weeks JR (1972) Long-term intravenous infusion. In: Methods in psychobiology (Meyer RD, ed), pp 155-168. London: Academic.

Willuhn I, Sun W, Steiner H (2003) Topography of cocaine-induced gene regulation in the rat striatum: relationship to cortical inputs and role of behavioural context. Eur J Neurosci 17:1053-1066.

Wilson MC, Schuster CR (1972) The effects of chlorpromazine on psychomotor stimulant self-administration in the rhesus monkey. Psychopharmacologia 26:115-126.

Winstanley CA, Dalley JW, Theobald DE, Robbins TW (2003) Global 5-HT depletion attenuates the ability of amphetamine to decrease impulsive choice on a delay-discounting task in rats. Psychopharmacology (Berl) 170:320-331

Wise RA, Bozarth MA (1987) A psychomotor stimulant theory of addiction. Psychol Rev 94:469-492.

Yano M, Steiner H (2005) Topography of methylphenidate (ritalin)induced gene regulation in the striatum: differential effects on c-fos, substance P and opioid peptides. Neuropsychopharmacology 30:901-915.

Zahm DS, Brog JS (1992) On the significance of subterritories in the "accumbens" part of the rat ventral striatum. Neuroscience 50:751-767. 